\title{
FITOPLÂNCTON DO ECOSSISTEMA ESTUARINO DO RIO ARIQUINDÁ (TAMANDARÉ, PERNAMBUCO, BRASIL): VARIÁVEIS AMBIENTAIS, BIOMASSA E PRODUTIVIDADE PRIMÁRIA.
}

\author{
CHRISTIANA KELLY DA SILVA GREGO ${ }^{1,2}$, FERNANDO ANTÔNIO DO NASCIMENTO FEITOSA ${ }^{1,2}$, MARCOS HONORATO DA SILVA ${ }^{1,2}$, \\ MARIA DA GLÓRIA GONÇALVES DA SILVA CUNHA ${ }^{1,2}$ \& GILSON ALVES NASCIMENTO FILHO ${ }^{1,3}$. \\ ${ }^{1}$ Universidade Federal de Pernambuco, Departamento de Oceanografia, Av. Arquitetura, s/n. 50.740-550 Recife - PE, Brasil. ${ }^{2}$ Laboratório de \\ Fitoplâncton; ${ }^{3}$ Laboratório de Oceanografia Química; ${ }^{4}$ chrisgrego@yahoo.com.br;
}

\begin{abstract}
RESUMO
O estuário do rio Ariquindá, foi analisado quanto a sua hidrologia, biomassa e produtividade fitoplanctônica entre agosto de 2005 e julho 2006, abrangendo o período chuvoso e de estiagem. As amostras foram coletadas mensalmente em três pontos fixos, na superfície da água durante a baixa-mar e preamar em maré de sizígia. A transparência da água foi menor no período chuvoso, o ambiente variou de oligoalino a eualino, as taxas de oxigênio dissolvido variaram desde zona de baixa saturação a supersaturada, os teores de silicato foram mais elevados no período chuvoso, enquanto os dos demais nutrientes (nitrito, nitrato e fosfato) foram baixos e não apresentaram padrão sazonal, espacial e nem entre os diferentes estágios de maré, o mesmo foi observado para a biomassa e a produtividade fitoplanctônica, exceto em relação aos estágios de maré. O estuário foi classificado como mesotrófico e a fração $<20 \mu \mathrm{m}$ do fitoplâncton foi a mais representativa para o ambiente, com percentual superior a $69 \%$ da biomassa fitoplanctônica. Com base nos teores de oxigênio dissolvido, sais nutrientes, biomassa e produtividade fitoplanctônica foi constatado que o estuário não sofre fortes impactos antrópicos, possui uma moderada capacidade produtiva, e a maré foi a forçante física condicionante do ambiente.
\end{abstract}

PALAVRAS CHAVE: hidrologia, clorofila a, produção fitoplanctônica, estuário

\section{ABSTRACT}

The Ariquindá River estuary of concerning the hydrology, phytoplankton biomass and productivity, in a monthly sampling programme from August 2005 to July 2006, covering the rainy and dry season, at the surface and at three fixed points, during low and high tides in full moon tide. The water transparency was low in the rainy season and the water salinity varied from oligohaline to euhaline. The dissolved oxygen rates varied from low saturated to supersaturated zone. The silicate values were higher in the rainy season, while the concentrations of the other nutrients (nitrite, nitrate and phosphate) were low and did not show seasonal and spatial patterns, nor even between the different tide stages, the some was observed for phytoplankton biomass and productivity, except in relationship the tides stages. The estuary was classified as mesotrophic and the phytoplankton size fraction $<20 \mu \mathrm{m}$ predominated in the environment, representing more than $69 \%$ of the microalgae biomass. The ranges of dissolved oxygen rates, nutrients concentrations, phytoplankton biomass and productivity shows that the estuary is not submitted to strong human impacts, it has a moderate productivity, and the tide pattern was the main controlling physical factor of the system.

KEY WORDS: hydrology, chlorophyll a, phytoplankton productivity; estuary.

\section{INTRODUÇÃO}

Os estuários estão entre os ecossistemas mais produtivos da Terra, o que evidencia sua importância econômica, além desta, possuem um relevante papel ecológico, por serem ambientes propícios para o ciclo de vida de várias espécies, servindo de berçários para muitos organismos, e via de migração para outros, principalmente no período de reprodução.

Dentre os organismos que integram os ambientes aquáticos, inserem-se as microalgas, que por serem fotossintetizantes, torna-se imprescindível seu nicho nesses ecossistemas, visto que, destes organismos vão depender de forma direta e indireta os demais níveis tróficos. Destaque se dá para o fitoplâncton, visto que, esta comunidade é globalmente considerada a mais importante dentre os produtores primários aquáticos (Boney 1989).

As variações temporais e espaciais que os organismos fitoplanctônicos sofrem nas suas composições e biomassa indicam as alterações ocorridas nos ecossistemas, sejam elas naturais ou antrópicas (Coelho et al. 2004), evidenciando sua capacidade de bioindicadores ambientais.

A determinação da biomassa fitoplanctônica através da clorofila a e da produtividade primária baseada no ${ }^{14} \mathrm{C}$, possibilitam avaliar a comunidade dos produtores primários aquáticos, e a resposta dos mesmos as condições ambientais, em especial ao enriquecimento por despejos orgânicos, sendo parâmetros fundamentais para monitoramento e avaliações de ecossistemas aquáticos (UNESCO 1997, Andersen et al. 2006).

Considerando que os estuários sofrem uma crescente pressão por impactos humanos e que os mais estudados são os sistemas temperados (Buford et al. 2008), tornam-se necessários trabalhos que objetivem diagnósticos de tais ecossistemas, utilizando como ferramenta as variáveis hidrológicas e dados quantitativos do fitoplâncton, visto que, são 
excelentes indicadores ambientais.

No ecossistema estuarino do rio Ariquindá, apesar da sua importância ecológica e sócioeconômica, até o presente momento só foram registrados trabalhos que envolvem a comunidade de cavalos-marinhos (Bruto-Costa et al. 2005, BrutoCosta 2007) e estrutura e padrão de zonação de mangues (Nascimento Filho 2007). Portanto, o trabalho teve o objetivo de realizar 0 primeiro levantamento sobre a comunidade fitoplanctônica e a hidrologia local, detectar a produtividade e a relação destes organismos com as variáveis ambientais, através de uma análise espacial, temporal e diferentes regimes de maré, o que permitiu evidenciar as condições hídricas do ecossistema, e servir como referência para diagnósticos futuros.

\section{MATERIAL E MÉTODOS}

\section{Localização da área do estudo}

O município de Tamandaré encontra-se situado ao sul do litoral Pernambucano a $110 \mathrm{~km}$ da cidade do Recife. Seu território abrange uma área de $98,9 \mathrm{~km}^{2}$, 17.281 habitantes, triplicando no período de veraneio, seu desenvolvimento se faz no turismo, comercio, pesca e agroindústria (açúcar e álcool). Tem suas terras e águas inseridas em três unidades de conservação APA Costa dos Corais, APA de Guadalupe e a Reserva Biológica de Saltinho (Botelho et al. 2000, FIDEM 2003).
O clima da região é tipicamente quente e úmido, Pseudotropical e do tipo AS', segundo o sistema de classificação de Köppen, caracterizado por um período chuvoso nos meses de março a agosto e um período de estiagem entre os meses de setembro a fevereiro. A pluviosidade anual oscila entre 1.850 a $2.364 \mathrm{~mm}$ (Andrade \& Lins 1971, Nimer 1979).

Sua bacia hidrográfica é formada por rios litorâneos, que, embora de dimensões reduzidas, desempenham importante papel na manutenção dos ecossistemas e das comunidades (CPRH 2003), dentre estes se incluem os rios Formoso, Mamucaba e llhetas.

O rio Ariquindá está inserido no Complexo estuarino do Rio Formoso, ( $8^{\circ} 41^{\prime} 22^{\prime \prime} S$ a $\left.35^{\circ} 05^{\prime} 50^{\prime \prime} \mathrm{W}\right)$ sendo formado pelos rios União, Porto do Tijolo, Porto Alegre e Cabrobó. Tem aproximadamente $10 \mathrm{~km}$ de extensão e uma profundidade média de $6 \mathrm{~m}$.

\section{Amostragem e pontos de coleta}

Para 0 presente trabalho foram realizadas coletas mensais de agosto de 2005 a julho 2006 abrangendo os diferentes períodos sazonais (chuvoso e estiagem) efetuadas durante a baixa-mar (BM) e preamar (PM) de um mesmo dia, em marés de sizígia, em três pontos fixos de amostragens na zona estuarina do rio Ariquindá: P1 a jusante; P2 porção intermediária e P3 a montante (Fig. 01). 


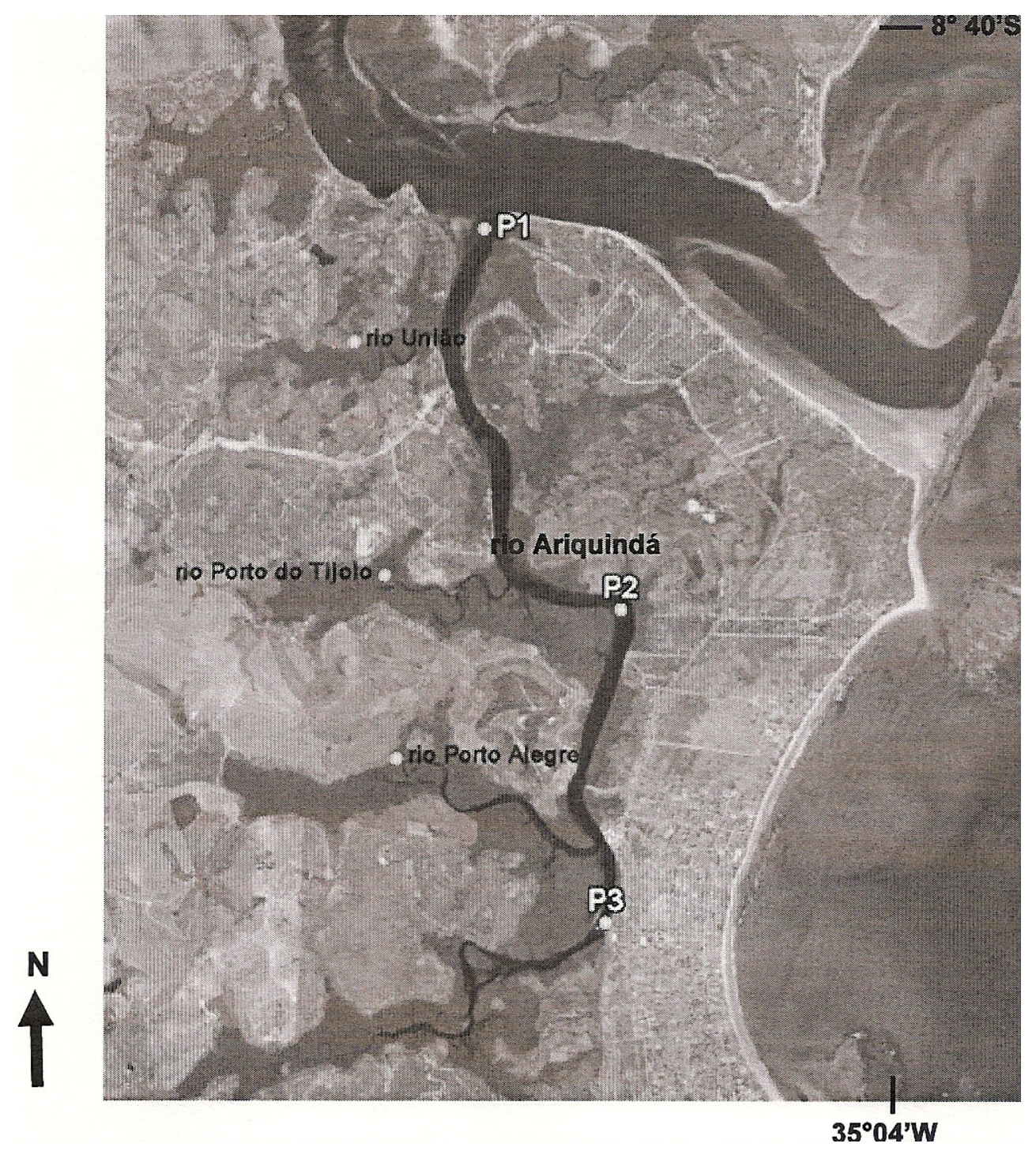

Figura 1 - Localização dos pontos de coleta no estuário do rio Ariquindá, Pe, Brasil.

As coletas das amostras hidrológicas e biológicas foram realizadas através de garrafa de Kitahara na camada superficial da água, e para os parâmetros de temperatura e salinidade, coletas adicionais foram feitas também na camada próxima ao fundo, para averiguar se existiria estratificação. As coletas para produção primária foram realizadas apenas nas baixa-mares, em função da necessidade da incubação in situ durante um período de três horas à luz do sol, o que tornou inviável as coletas nas preamares.

\section{Análise dos dados abióticos}

Os dados pluviométricos foram obtidos na Estação Meteorológica de Porto de Galinhas pertencente ao Instituto de Pesquisas Agropecuárias (IPA). As análises hidrológicas foram efetuadas no Laboratório de Química do Departamento de
Oceanografia da UFPE. A transparência e temperatura da água foram medidas in situ através de um disco de Secchi com cabo graduado em centímetros e termômetro comum de mercúrio, respectivamente; para a salinidade utilizou-se 0 método de Mohr-Knudsen, o oxigênio dissolvido pelo método de Winkler modificado, ambos descritos em Strickland e Parsons (1972); taxa de saturação do oxigênio dissolvido utilizou-se a "International Oceanographic Tables" (UNESCO 1973) correlacionando os valores de temperatura e salinidade; $\mathrm{o} \mathrm{pH}$ foi determinado por um $\mathrm{pH}$-metro Hanna instruments; para os sais nutrientes (nitrito, nitrato e fosfato) o método de Strickland e Parsons (op. cit.), e silicato, pelo de Grasshoff et al. (1983); para o material em suspensão total na água, Melo et al. (1975). 


\section{Análise dos dados bióticos}

A biomassa fitoplanctônica total e fracionada foram quantificadas através da medida da concentração de clorofila $a$, utilizando o método espectrofotométrico da UNESCO (1966). Para o fracionamento utilizou-se um copo de PVC com malha de náilon de $20 \mu \mathrm{m}$ para separar as frações menores do que $20 \mu \mathrm{m}$ (picofitoplâncton e nanofitoplâncton) e maior que $20 \mu \mathrm{m}$ (microfitoplâncton) (Platt et al. 1983). Para a produtividade fitoplanctônica foi utilizado o método do ${ }^{14} \mathrm{C}$ (Steemann-Nielsen, 1952), onde em alíquotas de $200 \mathrm{ml}$ de cada amostra foi inoculado $1 \mathrm{ml}$ da solução de bicarbonato de sódio $\left(\mathrm{NaHC}^{14} \mathrm{O}_{3}\right)$ de $10 \mu \mathrm{Ci}$ como traçador radioativo, com período de incubação de três horas in situ, e logo em seguida filtradas a vácuo em filtro Millipore de $0,45 \mu \mathrm{m}$ de porosidade e $47 \mathrm{~mm}$ de diâmetro, utilizando solução de Bray. As leituras dos filtros foram efetuadas no cintilador líquido do laboratório de fitoplâncton do Instituto Oceanográfico de São Paulo. A taxa de assimilação foi calculada através da relação entre valores de produtividade fitoplanctônica e os teores de clorofila a de acordo com Vollenweider et al. (1974).

\section{Análise numérica dos dados}

Foi realizada uma análise multivariada, efetuando uma associação das amostras através do cálculo da similaridade, utilizando os dados de todo o período coletado para verificar semelhanças nos fatores bióticos e abióticos, baseado na análise de correlação. Foi realizada também, uma análise cofenética para medir o ajuste dos dados, cujo valor >
0,8 é considerado bem ajustado (Rohlf \& Fisher 1968), e uma análise de componentes principais, para identificar os fatores responsáveis pela variância dos dados. Para tais tratamentos numéricos os dados foram padronizados, e o programa computacioanal utilizado foi o NTSYS (Numerical Taxonomy and Multivariate Analisys System) da Metagraphics Software Corporation, Califórnia - USA.

\section{Análise estatística}

Foi realizado o teste de Mann-Whitney, com o objetivo de avaliar cada parâmetro estudado em função dos fatores sazonalidade e maré, sendo considerados significativos os valores $\leq 0,05$. Utilizouse como referência (LEGENDRE \& LEGENDRE 1998).

\section{RESULTADOS}

\section{Pluviosidade}

O volume de chuvas para os anos de 2005 e 2006 na região estudada oscilou de um mínimo de 9,0 e $4,0 \mathrm{~mm}$ em novembro e outubro a um máximo de 464 e $415 \mathrm{~mm}$ de chuvas em junho, com precipitação total de 1.677 e $1.639 \mathrm{~mm}$, respectivamente. A sazonalidade na região foi bem marcante, com maior pluviosidade de abril a agosto (acima de $100 \mathrm{~mm}$ ). Não houve diferença significativa na precipitação pluviométrica entre os anos estudados $(p=0,91)$, nem destes com a média dos 17 anos $(p=0,87)$, porém a pluviosidade esteve ligeiramente abaixo do total de chuvas para a região (Fig. 2). 


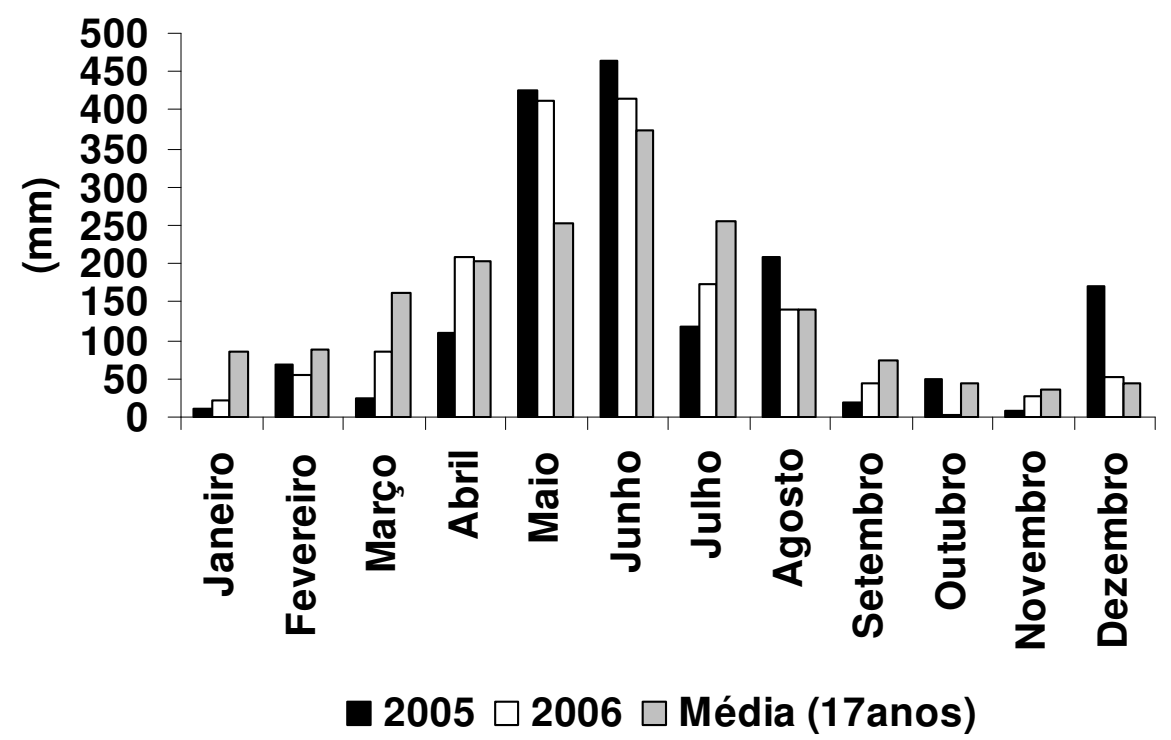

Figura 2 - Dados pluviométricos dos anos de 2005 e 2006 e as médias dos últimos 17 anos (1990-2006) para a região sul de Pernambuco

\section{Variáves hidrológicas}

As marés variaram entre o mínimo de $0.10 \mathrm{~m}$ e o máximo de $2.30 \mathrm{~m}$ nos meses de agosto e outubro de 2005 e em janeiro e março de 2006 (Fig. 3).

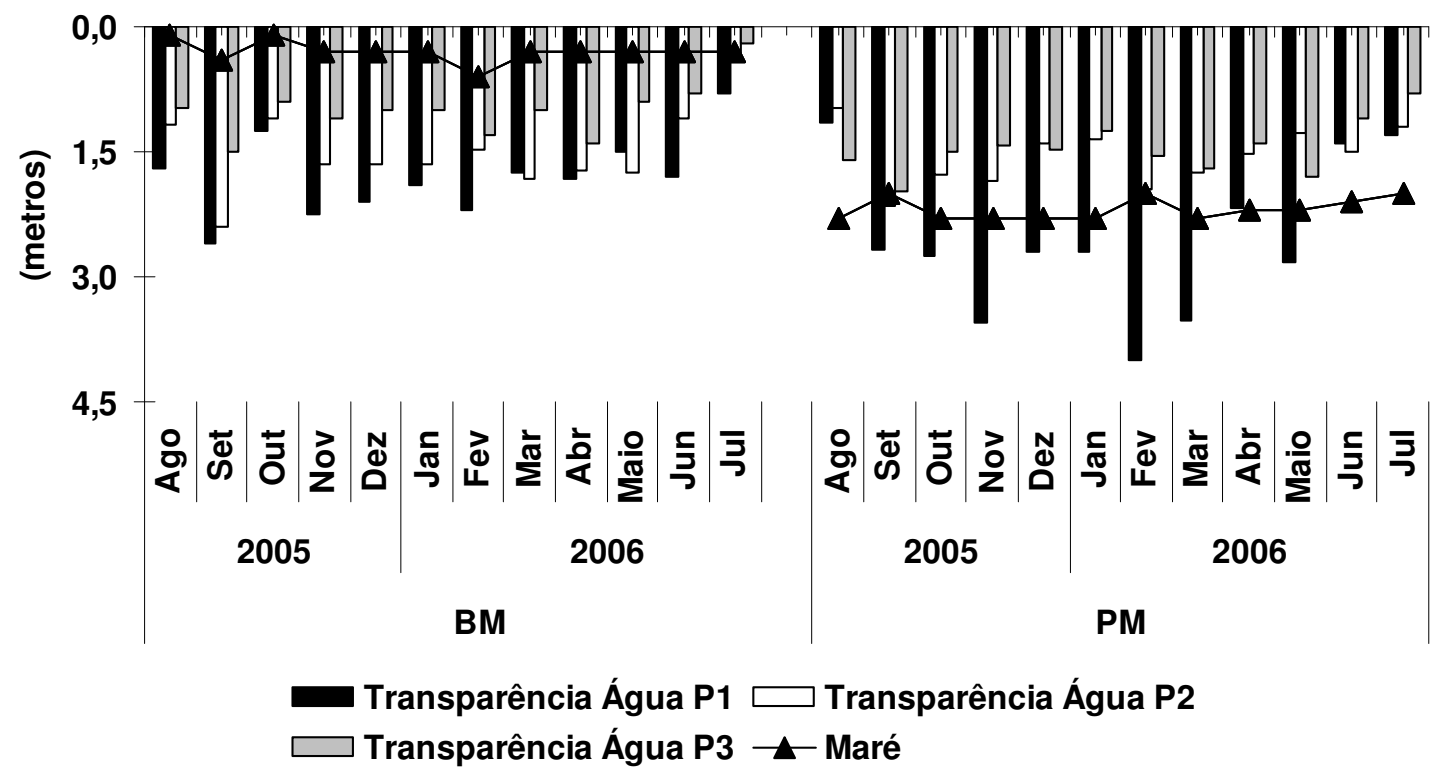

Figura 3 - Altura das marés para o Porto de Suape, PE, nos dias da coleta e variação da transparência da água nos três pontos de coleta do estuário do rio Ariquindá, PE, Brasil.

A transparência da água apresentou variação sazonal, com valores mais elevados durante 0 período de estiagem, sendo observado uma diferença significativa entre os dois períodos sazonais $(p=0,01)$. Os valores encontrados variaram de um mínimo de 0,20m no P3 em julho na BM a um máximo de $4,00 \mathrm{~m}$ no P1 em fevereiro na PM (Fig. 3). Observaram-se diferenças entre as marés $(p=0,03)$, com maiores transparências associadas às preamares, sendo este padrão mais evidenciado no $\mathrm{P} 1$, e um gradiente decrescente no sentido a montante do estuário (P3).

A temperatura variou de $25,00^{\circ} \mathrm{C}$ em todos os pontos e profundidades em junho a $31,50^{\circ} \mathrm{C}$ no $\mathrm{P} 1$ (fundo) e P3 (superfície) em abril, ambos na BM. 
Sazonalmente, essa diferença não foi significativa $(p=0,51)$. Também não ocorreram diferenças significativas nos estágios de maré $(p=0,50)$, e os valores de temperatura elevaram-se no sentido a montante (P3) do estuário (Fig. 4).

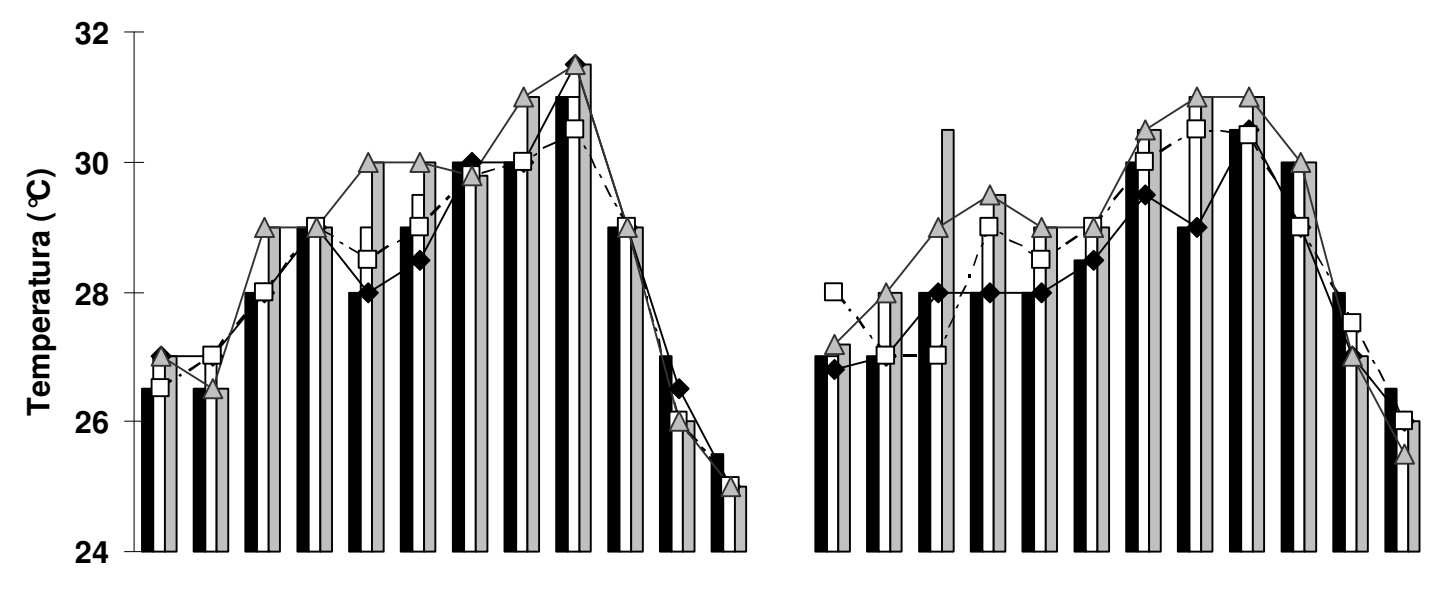

$\square \mathrm{P} 1 \mathrm{~S} \longleftarrow \mathrm{P} 2 \mathrm{~S} \longleftarrow \mathrm{P} 3 \mathrm{~S} \longrightarrow \mathrm{P} 1 \mathrm{~F}--\square \cdot-\mathrm{P} 2 \mathrm{~F} \triangle \mathrm{P} 3 \mathrm{~F}$

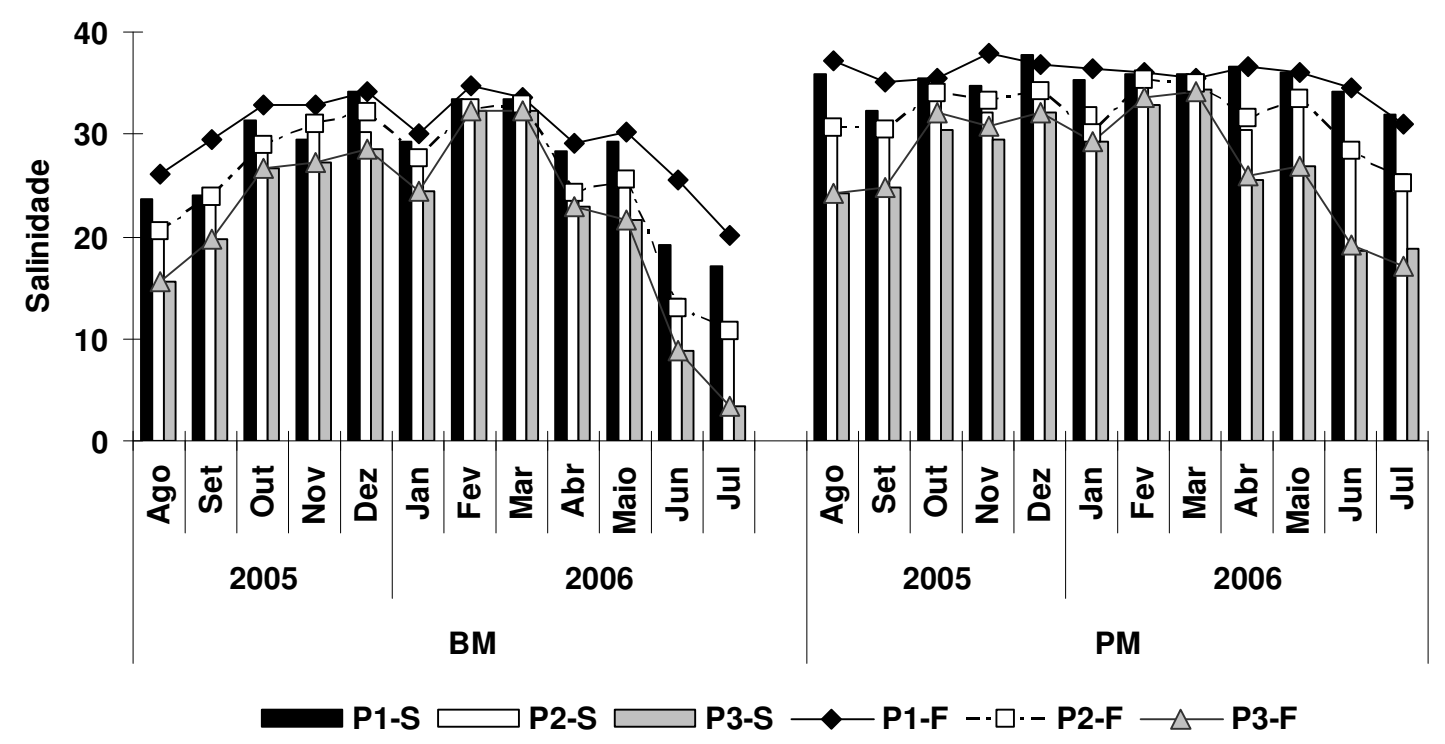

Figura 4 - Variação espaço-sazonal da temperatura e da salinidade d'água na superfície (S) e próxima ao fundo (F) no estuário do rio Ariquindá, PE, Brasil.

Para a salinidade observou-se uma variação sazonal com os menores teores durante o período chuvoso. As concentrações salinas variaram de 3,45 na superfície do P3 em julho na BM a 37,97 na camada próxima ao fundo do $\mathrm{P} 1$ em novembro na $\mathrm{PM}$ (Fig. 4). Espacialmente, o gradiente decresce no sentido a montante do estuário ( $\mathrm{P} 3$ ), não havendo estratificação salina. Os períodos sazonais e as marés foram significativamente diferentes apresentando $\mathrm{p}=0,00$ para ambas as variáveis.

O oxigênio dissolvido variou de $2,84 \mathrm{ml} . \mathrm{L}^{-1}$ no P3 no mês de junho na BM a $5,75 \mathrm{ml}^{-L^{-1}}$ no $\mathrm{P} 1$ em fevereiro na PM. Não foram observadas diferenças significativas entre os períodos chuvoso e de estiagem $(p=0,07)$. Ao contrário, à taxa de saturação do oxigênio dissolvido mostrou uma variação sazonal, com valores mais elevados durante o período de estiagem, apresentando diferença significativa $(p=0,01)$. O menor valor encontrado foi de $52,6 \%$ no $\mathrm{P} 3$ em junho na BM a 132,8\% no P1 em fevereiro na $P M$. Em relação às marés, tanto para o oxigênio dissolvido como para sua taxa de saturação, os maiores teores foram sempre registrados nas preamares (Fig. 5), sendo evidenciado diferença significativa $(p=0,00)$ entre os regimes de marés estudados. Espacialmente, observaram-se variações 
entre os diferentes pontos de coleta, com um padrão definido, as concentrações diminuindo no sentido a montante do estuário - P3, principalmente na preamar.

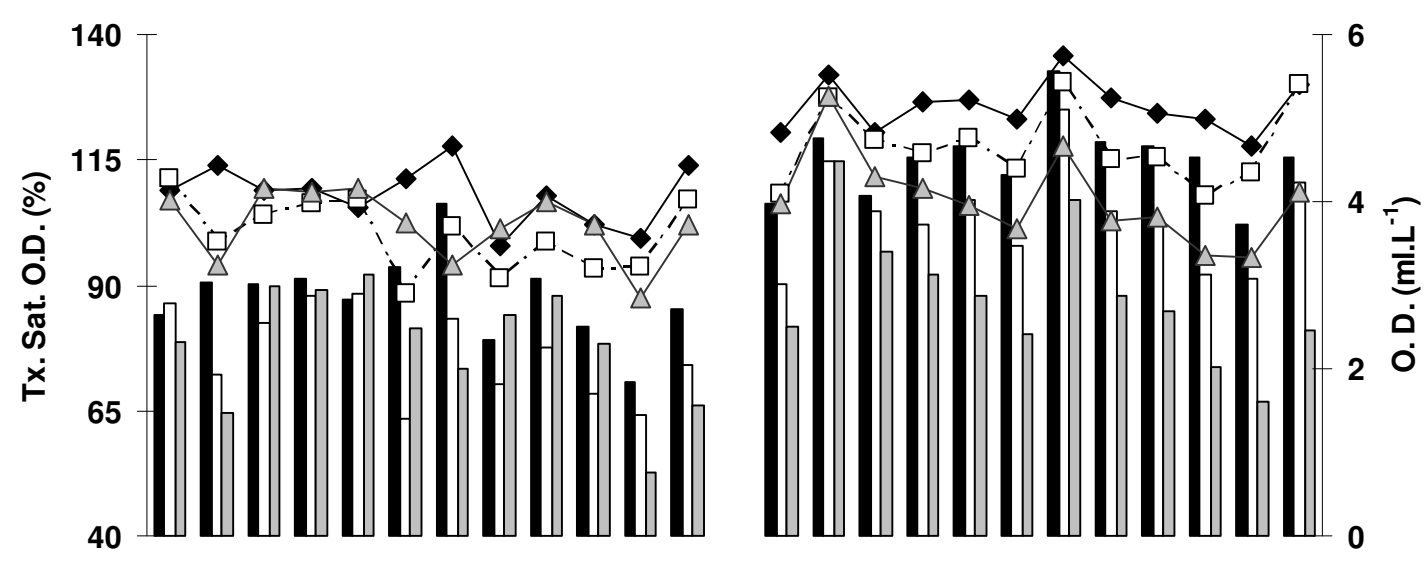

$\begin{array}{ll}\square \text { Tx. Sat. O.D. P1 } \square \text { Tx. Sat. O.D. P2 } \square \text { Tx. Sat. O.D. P3 } \\ \square \text { O.D. P1 } & -\square-\text { O.D. P2 }\end{array}$

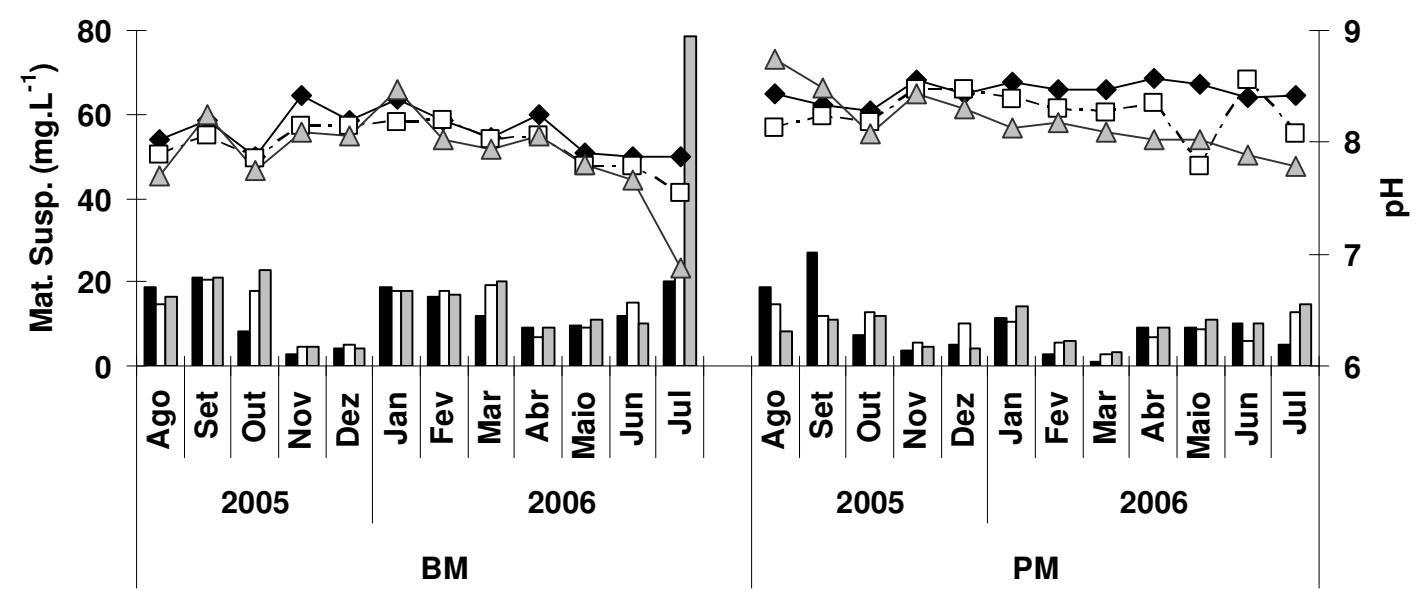

$\begin{array}{ll}\text { Mat. Susp. P1 } \square \text { Mat. Susp. P2 } \longleftarrow \text { Mat. Susp. P3 } \\ \longleftarrow \text { pH P1 } & \square-- \text { pH P2 }\end{array}$

Figura 5 - Variação espaço-sazonal do oxigênio dissolvido (O.D.), da taxa de saturação do oxigênio dissolvido (Tx.Sat. O.D.), do pH e do material em suspensão total (Mat. Susp.) na água no estuário do rio Ariquindá, Pe, Brasil.

Os valores de $\mathrm{pH}$ foram alcalinos, exceto no $\mathrm{P} 3$ onde foi encontrado o valor de 6,88 em julho na BM e o máximo de 8,74 em agosto na PM no mesmo ponto. Sazonalmente, observou-se variação apenas na baixa-mar com valores mais elevados no período de estiagem, a qual apresentou um $p=0,01$, ao contrário da preamar com um $p=0,37$. De uma forma geral os valores aumentaram no sentido a jusante do estuário e durante a preamar (Fig. 5), evidenciando uma diferença significativamente entre as marés $(p=0,00)$.

$O$ material em suspensão total na água apresentou pequenas diferenças entre os dois períodos não sendo significativas $(p=0,58)$, ao contrário dos diferentes estágios de maré $(p=0,01)$, com maiores concentrações durante à baixa-mar. $\mathrm{O}$ menor teor registrado foi de $0,95 \mathrm{mg} \mathrm{L}^{-1}$ no $\mathrm{P} 1 \mathrm{em}$ março na $P M$ enquanto a máxima foi de $78,00 \mathrm{mg} \mathrm{L}^{-1}$ no P3 em julho na BM (Fig. 5), em decorrência do deságüe do rio União.

Os nutrientes nitrogenados nitrito e nitrato, não apresentaram diferenças significativas entre os períodos sazonais $(p=0,55$ e $p=0,82)$ e as marés $(p=0,88$ e $p=0,65)$, respectivamente. Bem como também não apresentou um padrão espacial. Os 
teores oscilaram de não detectáveis para ambos os

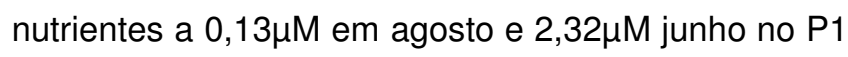

durante a PM para o nitrito e nitrato, respectivamente (Fig. 6).
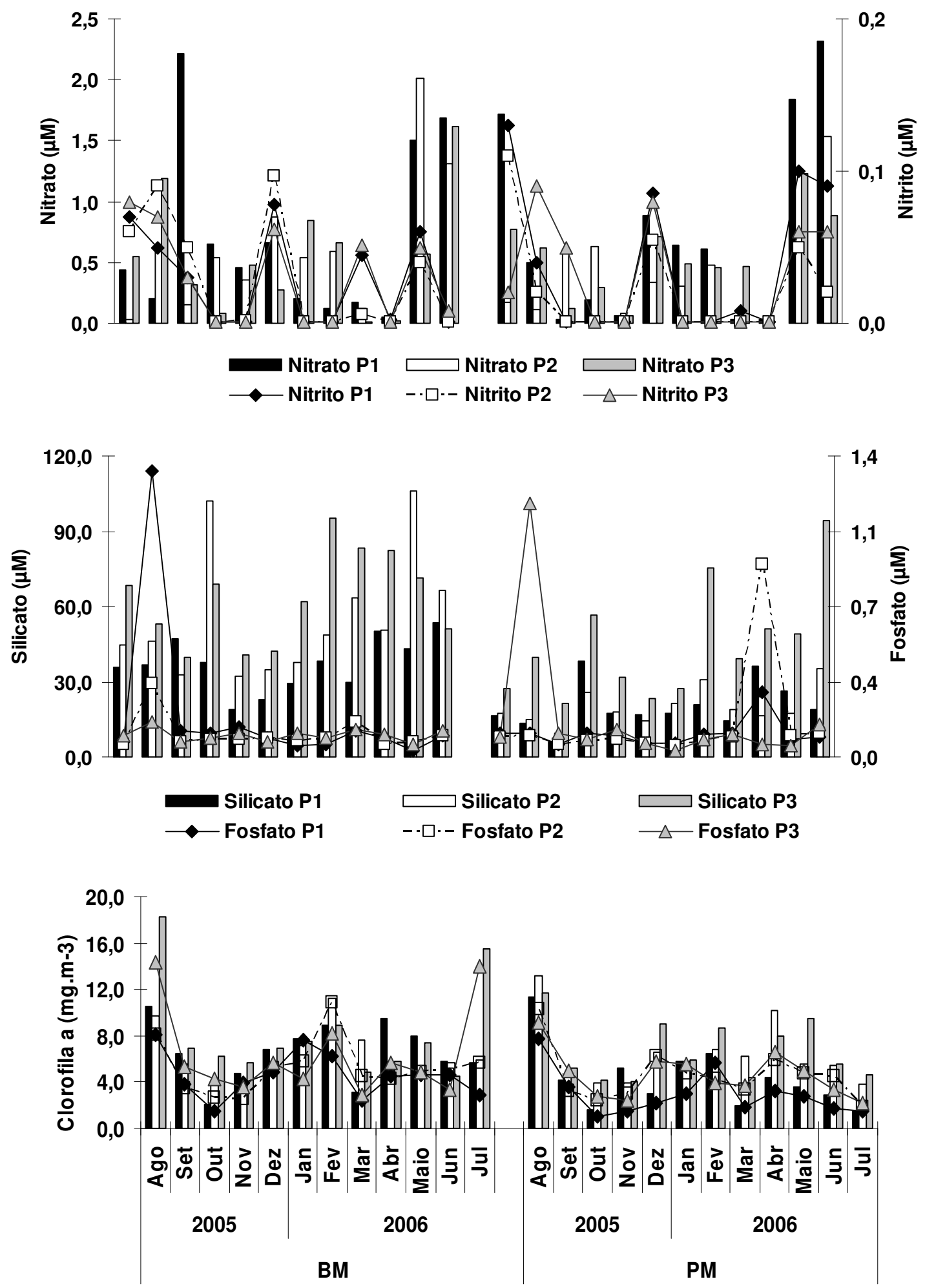

Clor. Tot. P1 $\square$ Clor. Tot. P2 $\square$ Clor. Tot. P3

$\longrightarrow$ Clor.Frac. P1 - $\boxminus-$ Clor.Frac. P2 $\multimap$ Clor.Frac. P3

Figura 6 - Variação espaço-sazonal dos sais nutrientes nitrito, nitrato, fosfato e silicato e da clorofila a total (Clor. Tot.) e fracionada (Clor. Frac.) no estuário do rio Ariquindá, Pe, Brasil. 
O fosfato também não apresentou diferenças significativas, no que se referem aos períodos sazonais $(p=0,60)$, as marés $(p=0,68)$ e à espacialidade. Foram observados elevações nos meses de setembro e maio. O teor mínimo encontrado foi de $0,03 \mu \mathrm{M}$ no $\mathrm{P} 1$ em junho na BM e no $\mathrm{P} 3$ em fevereiro na PM a um máximo de $1,33 \mu \mathrm{M}$ no P1 em setembro na baixa-mar (Fig. 6).

O silicato apresentou variação sazonal com as maiores concentrações relacionadas ao período de chuvas. Espacialmente, observou-se um gradiente decrescente em direção à jusante do estuário (P1), mostrando-se bem caracterizado por variações entre os regimes de marés estudados, sendo mais elevado nas baixa-mares. As concentrações variaram de $6,05 \mu \mathrm{M}$ no P1 em outubro na PM a $106,02 \mu \mathrm{M}$ no P2 em junho na BM (Fig. 6). Foram constatadas diferenças significativas entre os períodos $(p=0,01)$ e as marés $(p=0,00)$. 1,09mg. $\mathrm{m}^{-3}$ no P1 durante a PM nos meses de julho e outubro, respectivamente a máximos de $18,21 \mathrm{mg} \cdot \mathrm{m}^{-3}$ e $14,36 \mathrm{mg} \cdot \mathrm{m}^{-3}$ no P3 em agosto na BM, respectivamente (Fig. 6). Analisando os dados não houve diferenças significativas entre os períodos sazonais $(p=0,43)$, ao contrário para os regimes de marés $(p=0,03)$. Espacialmente, os valores seguem de uma forma geral um padrão crescente no sentido da montante do estuário.

A fração $<20 \mu m$ foi a que predominou no estuário em ambos os períodos e nos diferentes estágios de maré com índice superior a $69 \%$.

A produção fitoplanctônica, variou de $4,26 \mathrm{mgC} \cdot \mathrm{m}^{-3} \cdot \mathrm{h}^{-1}$ no $\mathrm{P} 1$ a $77,98 \mathrm{mgC} \cdot \mathrm{m}^{-3} \cdot \mathrm{h}^{-1}$ no P3 ambos em outubro, exceto no referido mês, não foi observado um padrão espacial. Houve variações ao longo do período estudado, porém sem apresentar diferenças significativas entre os períodos $(p=0,12)$, (Fig. 7).

\section{Biomassa, produtividade e taxa de assimilação do fitoplâncton.}

A concentração da clorofila a total e fracionada

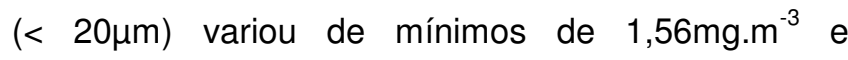

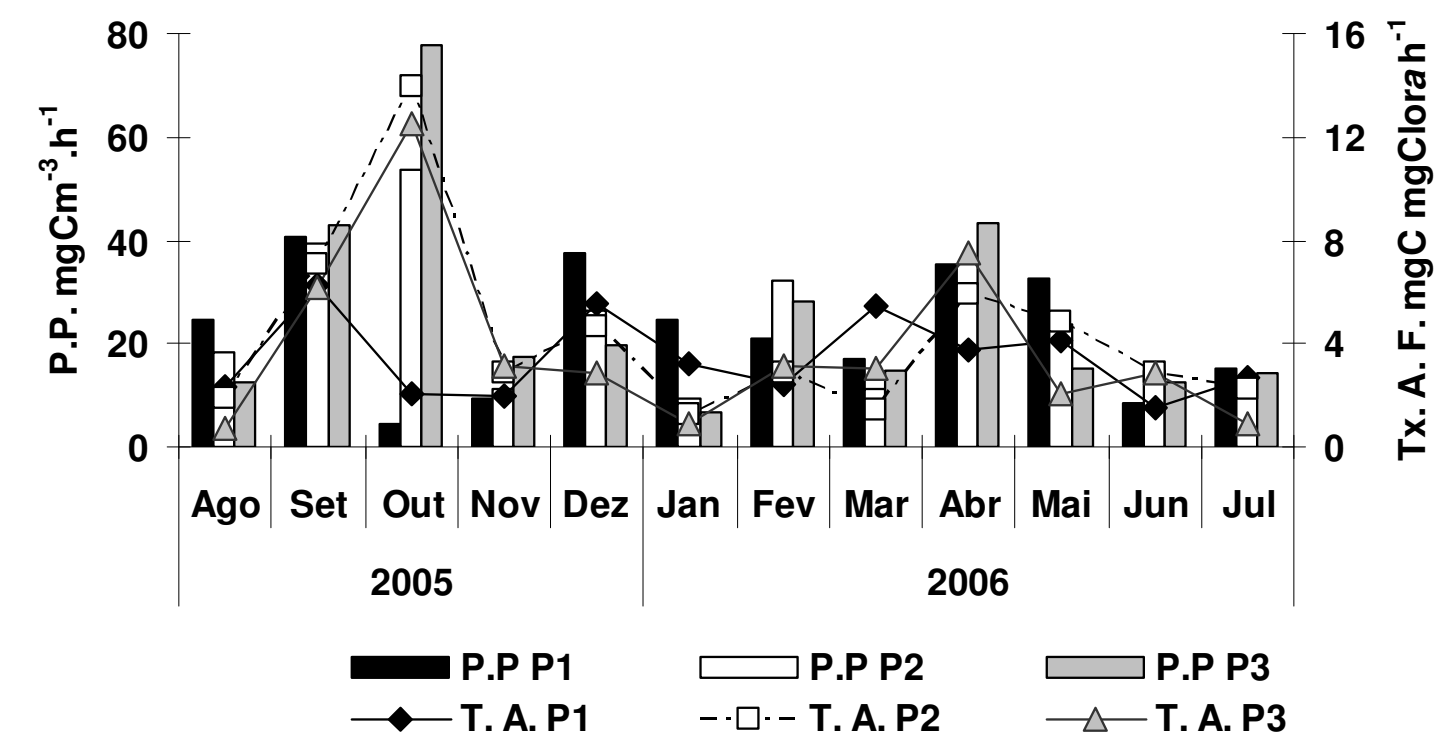

Figura 7 - Variação espaço-sazonal da produtividade (P.P.) e da taxa de assimilação (Tx. A. F.) fitoplanctônica no estuário do rio Ariquindá.

A taxa de assimilação variou de $0,69 \mathrm{em}$ agosto no P3 a 13,94 em outubro no P2, (Fig. 7), não foi registrado diferença significativa entre os períodos $p=0,13$.

\section{Análise de componentes principais (ACP)}

Em relação à Análise Multivariada, a associação das amostras produziu um dendrograma, que permitiu evidenciar três grupos através de um critério de similaridade entre os parâmetros 

GLÓRIA GONÇALVES DA SILVA CUNHA. GILSON ALVES NASCIMENTO FILHO.

analisados, os quais foram considerados bem ajustados, registrando uma análise cofenética com $r=$ 0,86 (Fig. 8). O grupo 1 ficou representado pela pluviometria, silicato e produtividade fitoplanctônica caracterizando o aporte continental; o grupo 2 associou o nitrito, nitrato, biomassa fitoplanctônica e material em suspensão, e o grupo 3 ficou representado pelo oxigênio, taxa de saturação do O.D (oxigênio dissolvido), maré, transparência da água e salinidade caracterizando o fluxo marinho. Na ACP, os três primeiros componentes explicaram $61 \%$ da variância dos dados, com $37 \%$ para o $1{ }^{\circ}$ componente, correlacionando positivamente silicato, material em suspensão, produção primária e estes, inversamente com maré, transparência, salinidade, oxigênio dissolvido, taxa de saturação do $O D$ e fosfato. $O$ componente 2 explicou $14 \%$ da variância e correlacionou inversamente a temperatura com nitrito, e o componente $3 \mathrm{com} 12 \%$ correlacionou à pluviometria com o nitrato, os quais foram inversos com a biomassa fitoplanctônica (Fig. 9; Tab. 1).

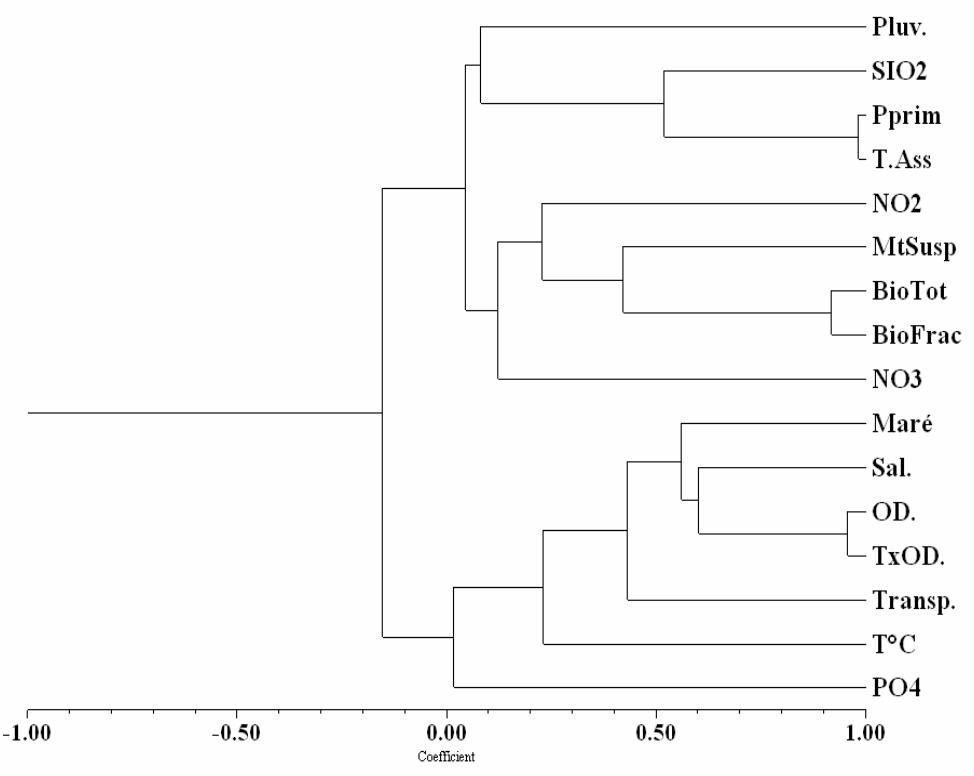

Figura 8 - Dendrograma mostrando os grupamentos formados pela associação das amostras.

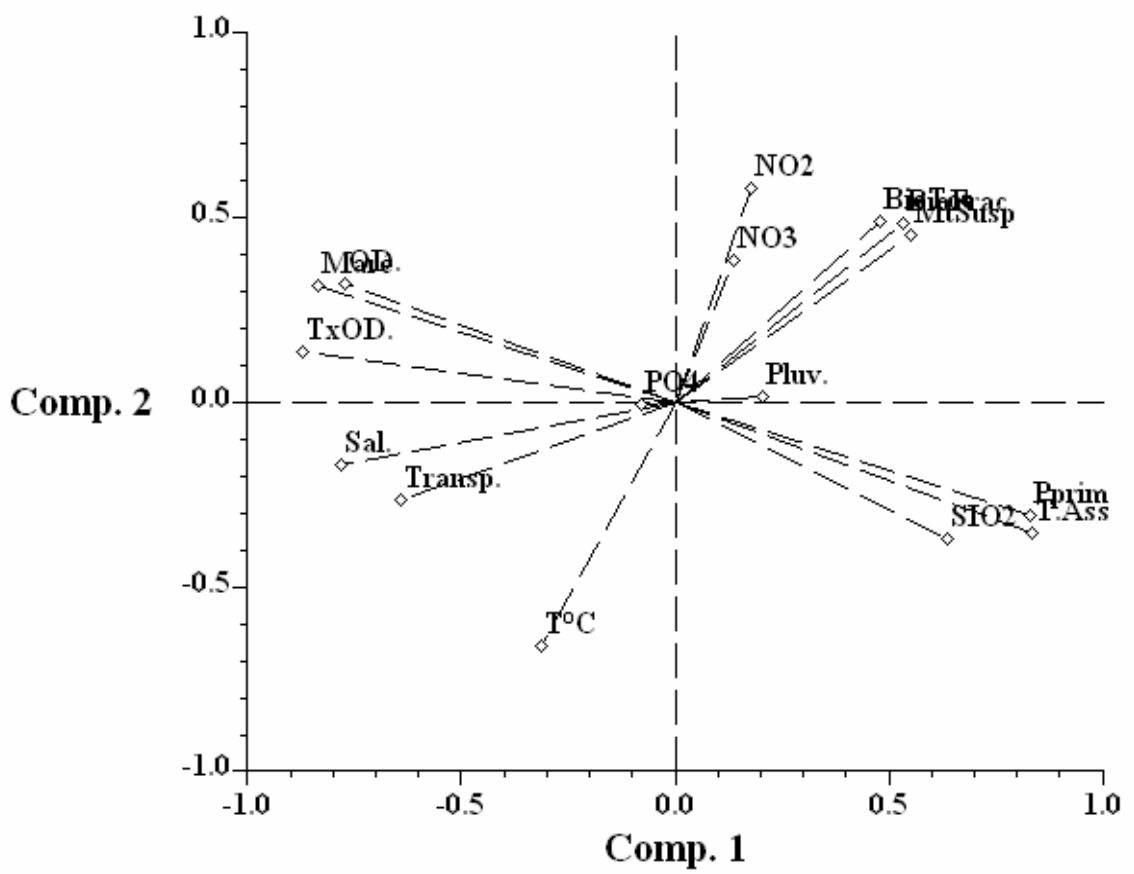

Figura 9 - Gráfico de escores e pesos para as duas primeiras componentes principais para as variáveis analisadas. 
Tabela 1 - Gráfico de escores e pesos para as duas primeiras componentes principais para as variáveis analisadas.

\begin{tabular}{|c|c|c|c|c|c|c|}
\hline Parâmetros & $\begin{array}{l}\text { Componente } \\
(37 \%)\end{array}$ & 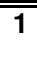 & $\begin{array}{l}\text { Componente } \\
(14 \%)\end{array}$ & 2 & $\begin{array}{l}\text { Componente } \\
(12 \%)\end{array}$ & 3 \\
\hline Pluviometria (Pluv.) & 0.2033 & & 0.0153 & & 0.4029 & \\
\hline Maré & -0.8360 & & 0.3186 & & 0.1270 & \\
\hline Transparência (Transp.) & -0.6429 & & -0.2632 & & -0.2353 & \\
\hline Temperatura $\left(\mathrm{T}^{\circ} \mathrm{C}\right)$ & -0.3144 & & -0.6585 & & -0.3753 & \\
\hline Salinidade (Sal) & -0.7864 & & -0.1682 & & -0.2238 & \\
\hline Oxigênio Dissolvido (O.D) & -0.7720 & & 0.3193 & & 0.1188 & \\
\hline Taxa saturação OD (Tx.O.D) & -0.8728 & & 0.1345 & & -0.1934 & \\
\hline Nitrito $\left(\mathrm{NO}_{2}\right)$ & 0.1788 & & 0.5814 & & -0.0520 & \\
\hline Nitrato $\left(\mathrm{NO}_{3}\right)$ & 0.1382 & & 0.3826 & & 0.6686 & \\
\hline Fosfato $\left(\mathrm{PO}_{4}\right)$ & -0.0809 & & -0.0063 & & -0.0087 & \\
\hline Silicato $\left(\mathrm{SIO}_{2}\right)$ & 0.6387 & & -0.3670 & & 0.2612 & \\
\hline Material Suspensão (Mt.Susp.) & 0.5533 & & -0.4559 & & 0.0468 & \\
\hline Produção Primaria (Pprim) & 0.8295 & & -0.3050 & & -0.2338 & \\
\hline Biomassa Total (Bio.Tot) & 0.5172 & & -0.4712 & & -0.6046 & \\
\hline Bio. Fracionada (Bio.Frac) & 0.5319 & & 0.4864 & & -0.5589 & \\
\hline Taxa Assimilação (T.Ass) & 0.8338 & & -0.3533 & & -0.1542 & \\
\hline
\end{tabular}

\section{DISCUSSÃO}

Os ciclos de marés e sazonais são fatores importantes que modulam e condicionam eventos na maioria dos estuários e outros sistemas litorais (Cloern et al. 1985). A pluviosidade mostra-se como um fator condicionante para alguns parâmetros hidrológicos e biológicos (Tundisi \& Tundisi 1976), seja de forma direta ou indireta, geralmente com uma influência bastante nítida sobre os nutrientes, material em suspensão, transparência da água, salinidade, biomassa e produtividade fitoplanctônica.

Diferente do que se esperava no estuário do rio Ariquindá, a pluviosidade só foi um fator condicionante para o silicato, a transparência da água e a salinidade, provavelmente, em função de ser um rio litorâneo, de planície e com pequena bacia hidrográfica. Também não se deve descartar que os totais de chuvas para os anos de coleta, estiveram ligeiramente abaixo do índice anual que, segundo Andrade \& Lins (1971), varia entre 1.850 a $2.364 \mathrm{~mm}$, o que levou a pluviosidade a apresentar um baixo peso na ACP.

Em outros estuários a pluviosidade foi um fator determinante nas variáveis ambientais, como evidenciado no complexo estuarino de Barra das Jangadas - PE (Branco et al. 2002, Branco 2008); no estuário do rio Formoso - PE (Honorato da Silva et al. 2004); no estuário do rio Timbó - PE (Grego et al. 2004); no estuário do rio Una - PE (Bastos et al.
2005); no complexo estuarino-Lagunar MundaúManguaba - AL (Melo Magalhães et al. 2004) e no estuário da Lagoa dos Patos - RS (Fujita \& Odebrecht 2007).

As menores transparências estiveram associadas a um maior transporte de materiais terrígenos para dentro do estuário, em detrimento ao período chuvoso e baixa-mar, fato marcante no mês de julho, com um deságue barrento de um dos contribuintes do Ariquindá, o rio União, que se encontra bastante assoreado. As maiores transparências da água foram favorecidas pelas preamares, que por serem águas mais limpas, provocaram uma maior dispersão das partículas em suspensão, como evidenciado pela associação direta e positiva entre a maré e a transparência.

Este padrão da transparência da água em função da maré e sazonalidade são comumente relatados para outros estuários como os rios llhetas e Mamucaba - PE (Losada et al. 2003) e o estuário do rio Formoso - PE (Honorato da Silva et al. 2004). Entretanto, atividades antrópicas podem mudar este padrão, a exemplo do porto de Corunã - Espanha (Varela \& Prego 2003) e no estuário do rio Timbó PE, (Grego et al. 2004), com menores transparências associadas à atividade de dragagem.

A maré foi um fator condicionante para a maioria das variáveis estudadas, proporcionando nas preamares as maiores concentrações de oxigênio dissolvido, taxa de saturação do O.D, transparência 
da água, e salinidade. Fato evidenciado no componente 1 , onde a maré e essas variáveis obtiveram os maiores pesos, reforçando a importância do fluxo marinho no ambiente. Porém, a relação inversa da maré com o silicato, o material em suspensão e a produtividade primária, demonstrou a influencia da baixa-mar sobre as variáveis (Tab. 1).

Noriega et al. (2005a) e Branco (2008) relataram que a variação temporal dos parâmetros (nutrientes inorgânicos e salinidade) estudados no estuário de Barra das Jangadas foi fortemente condicionada pela maré, semelhante ao padrão encontrado no estuário do rio Ariquindá.

Quanto à temperatura, observou-se que esteve dentro do padrão esperado para regiões tropicais, apresentando baixa amplitude, visto que, a mudança ocorre de forma gradativa ao longo dos meses. A ausência de estratificação térmica e salina na coluna d'água classificou, quanto ao padrão de circulação, como um estuário verticalmente homogêneo.

O mesmo padrão de circulação também ocorre em outros estuários, a exemplo do Canal de Bertioga (SP), onde não foi observada estratificação térmica/salina durante as marés de sizigia (Gianesella et al. 2000), nos rios llhetas e Mamucaba - PE e no sistema estuarino de Barra das Jangadas - PE, com forte hidrodinâmica local (Losada et al. 2003, Noriega et al. 2005b). Situação diferente foi observada no estuário Gamtoos (África do Sul), onde a morfologia do ambiente associado ao fluxo fluvial resultou em um ecossistema altamente estratificado (Snow et al. 2000).

A salinidade foi um parâmetro fundamental para caracterizar o fluxo marinho, visto sua correlação direta com a maré, e inversa com silicato e material em suspensão. Observou-se que nas preamares, mesmo nos períodos de maior pluviosidade, os índices de chuvas não foram suficientes para modificar de forma brusca os teores de sais no decorrer do estudo, diferente, do visualizado nas baixa-mares, nos meses de junho e julho. De acordo com a classificação de Veneza, que leva em consideração os valores de salinidade, o ambiente variou de oligoalino a eualino.

Dentre os gases dissolvidos na água, o oxigênio é um dos mais importantes na dinâmica e na caracterização de ecossistemas aquáticos. (Esteves
1998). Nesse sentido, Macêdo \& Costa (1978) elaboraram para os estuários do nordeste um sistema de classificação para caracterizar a qualidade hídrica baseado na taxa de saturação do oxigênio dissolvido, enquadrando: Zona supersaturada (> 100\%); Zona saturada (75 a 100\%); Zona de baixa-saturação (50 a $75 \%$ ); Zona semi-poluída (25 a 50\%) e Zona poluída (<25\%). Levando-se em consideração o sistema de classificação acima, verificou-se que o estuário do rio Ariquindá encontra-se isento de poluição orgânica, tendo em vista que $80 \%$ das amostras apresentaram concentrações superiores a $80 \%$ de saturação.

Trabalhos realizados em estuários próximos ao estudado, também não registraram índices de poluição, como nos rios Ilhetas e Mamucaba (Losada et al. 2003), situado no mesmo município e no estuário do rio Formoso (Honorato da Silva et al. 2004), evidenciando que as atividades antrópicas realizadas a cerca destes ecossistemas não incrementaram uma grande carga de matéria orgânica. Enquanto nos estuários de Barra das Jangadas e do rio Timbó (PE), foram registrados índices de zona semi-poluída (Branco, 2008; Grego et al. 2004) e na bacia do Pina, zona poluída (Feitosa et al. 1999), relacionados a despejos domésticos e industriais.

No estuário do rio Ariquindá os valores alcalinos de $\mathrm{pH}(>7)$, os quais são típicos de águas costeiras, evidenciaram a grande influência marinha e, provavelmente, baixa processos de decomposição de matéria orgânica, corroborando para a condição de área não poluída.

Os picos ocorridos de material em suspensão e clorofila $a$, juntamente com a correlação direta entre esses dois parâmetros, sugeriram que grande parte desse material foi de natureza biológica (planctônica). O mesmo padrão na ACP foi relatado por Bastos et al. (2005) no estuário do rio Una e Noriega et al. (2005b) em Barra das Jangadas, onde os autores afirmaram ser o material em suspensão de natureza orgânica.

Segundo Dias et al. (2004) o material em suspensão na água pode ser de origem autóctone (formado por atividade sintetizante dos organismos que compõem a população local), o que deve ter ocorrido no Ariquindá, ou alóctone provindo da lixiviação do solo ou pela ação humana através de 
esgotos e indústrias.

As baixas concentrações de nitrato e fosfato observadas podem estar associadas: às condições geográficas do rio, não permitindo um grande transporte de águas fluviais para o estuário, a mistura da água marinha com a fluvial, bem como ao consumo pelo fitoplâncton.

Carmouze (1994) reporta que, a velocidade de regeneração para a formação do nitrato, em geral, é menor do que a assimilação pelos produtores primários, resultando em baixas concentrações do nutriente. E segundo Esteves (1998), as altas temperaturas, nos ecossistemas tropicais, levam a uma rápida assimilação e incorporação do fosfato a biomassa, tornando muito baixa a concentração deste nutriente no ambiente, exceto nos eutrofizados.

A correlação direta entre o fosfato e a maré alta, mostrou que o aporte marinho pode ter adicionado fósforo ao ambiente, e que houve a liberação de $\mathrm{PO}_{4}$ do sedimento em detrimento a entrada da água salgada, visto que, a dinâmica deste elemento nos ambientes costeiros e estuarinos, estão diretamente relacionadas ao sedimento, onde ocorre sua mineralização.

As maiores concentrações de fosfato em setembro, provavelmente estiveram associadas a um maior fluxo de embarcações na alta estação, fato já observado por Bruto-Costa (2007) no estuário Ariquindá.

As concentrações dos nutrientes quando comparadas com outros estuários, também permitiram caracterizar o ecossistema como um ambiente ainda não poluído, segundo Aminot \& Chaussepied (1983), os quais reportaram como valores máximos para áreas estuarinas não impactadas até $1.00 \mu \mathrm{M}$ para nitrito e fosfato $\mathrm{e}$ $15,00 \mu \mathrm{M}$ para o nitrato.

Áreas com baixas concentrações destes nutrientes também foram observadas no estuário da Lagoa dos Patos (Fujita \& Odebrecht 2007) e na zona estuarina e baia de Tamandaré, sendo considerada oligotrófica mesmo recebendo influência de dois rios: Ilhetas e Mamucaba (Rosevel Silva et al. 2004, Losada et al. 2003). Por outro lado, ecossistemas com altas concentrações de nutrientes, caracterizando ambientes poluídos, associados ao desenvolvimento urbano, industrial e atividades agrícolas, foram reportadas nos estuários da bacia do Pina (Brasil), e do rio Tamsui (Taiwan) por Feitosa et al. (1999) e Wu \& Chou (2003), respectivamente.

As altas concentrações de silicato estiveram relacionadas a uma maior descarga fluvial, visto que, este nutriente é de origem terrígena. A correlação direta do silicato com a produção e a biomassa fitoplanctônica no componente 1 , evidenciou a importância deste nutriente para o crescimento desta comunidade, em especial o grupo das diatomáceas, haja vista, ser a comunidade mais representativa nos ecossistemas costeiros.

Wu \& Chou (2003) no estuário do rio Tamsui (Taiwan) relataram que o enriquecimento com silicato tem elevado notavelmente a produção fitoplanctônica, principalmente das diatomáceas, do que enriquecimentos de nitrogênio ou fósforo, os autores relataram ainda uma correlação direta entre o nutriente e a biomassa das microalgas.

No entanto, pode ser visualizada também relação inversa do silicato com a biomassa fitoplanctônica, como o observado por Aktan et al. (2005) na baía de Ízmit (Turquia), onde os autores associaram a pouca disponibilidade do nutriente no período de estiagem e ao consumo pelas diatomáceas.

Possivelmente em virtude de o rio Ariquindá ser litorâneo, de planície com pequena bacia hidrográfica e pouca extensão foi que a produtividade, a biomassa e a taxa de assimilação do fitoplanctônica no estuário não apresentaram diferenças significativas quanto aos períodos estudados e a espacialidade.

Fujita \& Odebrecht (2007) no estuário da Lagoa dos Patos (RS), não encontraram diferenças sazonais da clorofila $a$, havendo inclusive, semelhanças nos valores médios. Os autores reportaram que as concentrações de clorofila a foram controladas pela variação do fluxo fluvial e dos ventos, o mesmo não se pode dizer para o estuário Ariquindá, uma vez que esses parâmetros físicos não foram aferidos.

A relação inversa da maré com as variáveis biológicas, mostrou que a baixa-mar foi um fator condicionante para a biomassa fitoplanctônica no estuário, em detrimento ao aumento das concentrações de silicato. Da mesma forma, a correlação positiva da produção primária e biomassa com o silicato no componente 1 , e a inversa entre o 
nitrato e a biomassa no componente 3 , confirmaram a relação destes nutrientes para o incremento da biomassa, o que conduziu a uma maior taxa de assimilação.

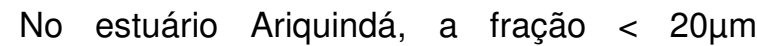
contribuiu com uma média de $72 \%$ da biomassa total, semelhante ao ocorrido no rio Jaguaribe, na bacia do Pina; no estuário de Barra das Jangadas (SantosFernandes et al. 1998, Feitosa et al. 1999, Branco et al. 2002, Branco 2008), bem como na baía Chesapeake, USA (Marshall et al. 2006). Neste sentido, tal fração tem contribuído com percentuais de 80 a 100\% da biomassa e produtividade primária em ecossistemas tropicais e temperados (SantosFernandes op. cit.). Para Souza et al. (2004) a distribuição de tamanho dos organismos fitoplanctônicos é de grande importância ecológica, porque definem a qualidade de alimento disponível para os subsequentes níveis tróficos das teias.

A capacidade das células do fitoplâncton de sintetizar matéria orgânica depende da disponibilidade de carbono, nitrogênio e fósforo no meio, desta forma a produtividade e a biomassa fitoplanctônica refletem as condições de oligotrofia, mesotrofia e eutrofia da água e constituem bons indicadores de alterações ambientais (Franco et al. 2006). Neste sentido, taxas de produtividade fitoplanctônica têm sido incluídas como um dos componentes de estados tróficos para avaliações de ecossistemas aquáticos (Smith 2007).

Os valores de produção primária permitiram considerar 0 estuário como moderadamente produtivo, da mesma forma como os reportados por Franco et al. (2006) no estuário do rio Tejo (Lisboa), inclusive, com semelhanças entre os valores com a presente pesquisa. Entretanto, por se tratar de um estuário temperado os autores encontraram diferenças marcantes entre os períodos.

Não foi detectado através dos valores de biomassa e da produtividade fitoplanctônica efluentes domésticos sobre o ambiente, apesar do estuário se encontrar em uma área urbanizada e com atividades turísticas.

Alguns autores reportam alta produtividade para zonas estuarinas do nordeste, a exemplo de Passavante et al. (2003) no estuário do rio Botafogo e Santos-Fernandes (2000) no Jaguaribe, indicando que os índices foram elevados, porém sem indicar processos de eutrofização. No entanto, Feitosa \& Passavante (1991/93) registraram um alto grau de produtividade primária $\left(756,21 \mathrm{mgCm}^{-3} \cdot \mathrm{h}^{-1}\right)$ na bacia do Pina, e enquadraram o ecossistema como poluído, principalmente por efluentes domésticos. Para Wu \& Chou (2003) no estuário do rio Tamsui (Taiwan) o desequilíbrio no suprimento dos nutrientes como resultado do incremento de águas poluídas é a possível causa da diminuição na produtividade primária nas últimas décadas.

A taxa de assimilação do fitoplâncton é uma relação entre os valores de produtividade e clorofila $a$, com intuito de classificar os ecossistemas aquáticos (Vollenweider et al. 1974). Os valores situados entre 0 a 3, são tidos como oligotróficos; entre 3 e 5, mesotróficos e superior a 5 , eutróficos. Levando-se em conta este critério de classificação, pode-se dizer que o estuário Ariquindá variou de oligotrófico a eutrófico, porém com tendência a mesotrófico.

A integração das variáveis estudadas permitiu caracterizar o estuário como uma área livre de fortes impactos antrópicos, a comunidade fitoplanctônica mostrou uma moderada capacidade produtiva, e a maré foi a variável condicionante do ambiente.

\section{AGRADECIMENTOS}

A Coordenação de Aperfeiçoamento de Pessoal de Nível Superior (CAPES), pela concessão da bolsa (nível Doutorado) e ao Centro de Pesquisa e Gestão de Recursos Pesqueiros do Litoral Nordeste (CEPENE - IBAMA), pelo apoio logístico ao longo do trabalho de campo, os quais viabilizaram a realização deste trabalho. E mais, aos avaliadores e relatores, pelas construtivas sugestões, as quais grandemente melhoraram o artigo.

\section{LITERATURA CITADA}

AKTAN, Y, I TÜFEKCV, HI TÜFEKCV \& G AYKULU. 2005. Distribution patterns, biomass estimates and diversity of phytoplankton in Ízmit Bay (Turkey). Estuar. Coast. Shelf Sci. 64: 372-384

AMINOT, A \& M CHAUSSEPIED. 1983. Manuel des analyses chimiques en milieu marin. CNEXO, Brest. 395p.

ANDERSEN JH, L SCHLÜTER \& G ÆERTEBJERG. 2006. Coastal eutrophication: recent developments in definitions and implications for monitoring strategies. J. Plankton Res. 28: 621628.

ANDRADE, GO \& RC LINS. 1971. Os climas do Nordeste. In: VASCONCELOS SOBRINHO, J. (Ed). As regiões naturais do Nordeste, o meio e a civilização. CONDEPE, Recife. 3(4): 95138.

BASTOS, RB, FAN FEITOSA \& K MUNIZ. 2005. Variabilidade espaçotemporal da biomassa fitoplanctônica e hidrologia no estuário do rio Erro (Pernambuco - Brasil). Trop. Oceanogr. 33. 1:1-18. 
BONEY, AD. 1989. Phytoplankton. $2^{\circ}$ ed, London: E, Arnald. 118p.

BOTELHO, ERRO, FMC SANTOS \& ACP PONTES. 2000. Algumas considerações sobre o uso da redinha na captura do caranguejo-uça, Ucides cordatus (Linnaeus, 1763) no litoral sul de Pernambuco - Brasil. Bolm. Tecn. Cient. CEPENE, Tamandaré. 8(1): 55-71.

BRANCO, ES, FAN FEITOSA \& MJ FLORES MONTES. 2002. Variação sazonal e espacial da biomassa fitoplanctônica relacionada com parâmetros hidrológicos no estuário de Barra das Jangadas (Jaboatão dos Guararapes - Pernambuco Brasil). Trop. Oceanogr. 30(2): 79-96.

BRANCO, ES. 2008. Influência das Variáveis Ambientais na Comunidade Fitoplanctônica Estuarina. Recife, Editora Universitária. 266p.

BRUTO-COSTA, LV, MB ARAÚJO \& TPR OLIVEIRA. 2005 Abundância e densidade populacional de cavalos-marinhos (SYNGNATHIDAE: Hippocampus) no estuário do rio Ariquindá, PE. In Anais da $9^{\circ}$ Jornada de Iniciação Cientifica PIBIC/FACEP/CNPQ. 2005.

BRUTO-COSTA, LV. 2007. Efeito de marolas produzidas por embarcações a motor em cavalos-marinhos (SYNGNATHIDAE: Hippocampus) no estuário do rio Ariquindá, PE. Monography. Federal University of Pernambuco, Brazil.

BUFORD MA, DM ALONGI, AD McKINNON \& LA TROTT. 2008. Primary production and nutrient in a tropical and macrotidal estuary, Darwin Harbour Australia. Estuar. Coast. Shelf Sci. 30: 1-9.

CARMOUZE, JP. 1994. O metabolismo dos ecossistemas aquaticos: Fundamentos teoricos, meodos de estudo e análises químicas. São Paulo, FAPESP, Edgard Blücher. 254p.

CLOERN, JE, BE COLE, RLJ WONG \& AE ALPINE. 1985. Temporal dynamics of estuarine phytoplankton - a case-study of San-Francisco Bay. Hydrobiologia 129:153-176.

COELHO, PA, LMA BATISTA-LEITE, MAC SANTOS \& MAF TORRES. 2004. O manguezal. In: ESKINAZI-LEÇA, E, S NEUMANN-LEITÃO \& MF COSTA (Org.). Oceanografia - Um cenário tropical. Bagaço, Recife. 641-688.

COMPANHIA PERNAMBUCANA DO MEIO AMBIENTE - CPRH. Diagnóstico Sócio-Ambiental APA de Guadalupe. 2003. Disponível em: htpp://www.cprh.pe.gov.br. Acesso em: 03/10/2005.

DIAS, J, FF COSTA \& WN LIMA. 2004. Caracterização química da matéria orgânica transportada para águas estuarinas (Nordeste do Estado do Pará). In: I Congresso Brasileiro de Oceanografia e XIV Semana Nacional de Oceanografia. São Paulo, p. 291.

ESTEVES, F. 1998. Fundamentos de Limnologia. $2^{\circ}$ Ed. Rio de Janeiro, Interciência. 602p.

FEITOSA, FAN \& PASSAVANTE JZO. 1991/93. Variação Sazonal da Produção Primária do Fitoplâncton da Bacia do Pina (Recife, PE). Trab. Oceanogr. Univ. Fed. Pe. 22: 65-82.

FEITOSA, FAN, FCR NASCIMENTO \& KMP, COSTA. 1999. Distribuição espacial e temporal da biomassa fitoplanctônica relacionada com parâmetros hidrológicos na Bacia do Pina (Recife, PE). Trab. Oceanogr. Univ. Fed. Pe. 27(2): 1-13.

FIDEM. Fundação de Desenvolvimento da Região Metropolitana do Recife, CONDEPE. 2003. Tamandaré um arrastão de artes e oficinas. CONDEPE. $44 p$

FRANCO, V, G CABEÇADAS \& M NOGUEIRA. 2006. Produtividade primária no estuário do Tejo e zona costeira adjacente. In Anais da I Conferencia Lusófona sobre o Sistema Terra - CluSTer. FC-UL. Lisboa.

FUJITA, CC \& C ODEBRECHT. 2007. Short term variability of chlorophyll a and phytoplankton composition in a shallow area of the Patos Lagoon Estuary (Southern Brazil). Atlântica. 29(2): 93-106.

GIANESELLA, SMF, FMP SALDANHA-CORRÊA \& C TEIXEIRA. 2000. Tidal effects on nutrients and phytoplankton distribution in Bertioga Channel, São Paulo, Brasil. Aq. Ecosyst. Health Manage. 3: 533-544

GRASSHOFF, K, M EHRARDT, \& K KREMELING. 1983. Methods of sea water analysis. 2 ed. Verlag Chemie, New York. $419 p$

GREGO, CKS, FAN FEITOSA, M HONORATO DA SILVA \& MJ FLORES MONTES. 2004. Distribuição espacial e sazonal da clorofila a fitoplanctônica e hidrologia do estuário do rio Timbó (Paulista, PE). Trop. Oceanogr. 32(2): 181- 199.

HONORATO DA SILVA, M, JZO PASSAVANTE, MGG SILVACUNHA, DA NASCIMENTO-VIEIRA, CKS GREGO \& K MUNIZ. 2004. Distribuição Espacial e Sazonal da Biomassa Fitoplanctônica e dos Parâmetros Hidrológicos no Estuário do Rio Formoso (Rio Formoso, Pernambuco, Brasil). Trop. Oceanogr. 32 (1): 89-106.

LEGENDRE, P \& L LEGENDRE. 1998. Numerical Ecology. Developments in Environmental Modelling 20. Elsevier Science, Amsterdam. 853p.

LOSADA, APM, FAN FEITOSA \& IC LINS. 2003. Variação sazonal e espacial da biomassa fitoplanctônica nos estuários do rios Ilhetas e Mamucaba (Tamandaré - PE), relacionada com parâmetros hidrológicos. Trab. Oceanogr. Univ. Fed. Pe. 28(2) 1-18.

MACEDO, SJ \& KMP COSTA. 1978. Estudo ecológico da região de Itamaracá Pernambuco - Brasil, condições hidrológicas do estuário do rio Botafogo. Cienc. Cult. 30(7): 346-368.

MARSHALL, HG, RV LACOUTURE, C BUCHANAN \& JM JOHNSON. 2006. Phytoplankton assemblages associated with water quality and salinity regions in Chesapeake Bay, USA. Estuar. Coast. Shelf Sci. 67: 1-9.

MELO-MAGALHÃES, EM, ML KOENING \& CL SANT'ANNA. 2004. Fitoplâncton e variáveis ambientais nos canais do sistema estuarino lagunar Mundaú/Mangaba, Alagoas, Brasil. Hoehnea. 31(1): 73-86.

MELO, U, CP SUMMERHAYES \& LG TORNER. 1975. Metodologia para o estudo do material em suspensão na água do mar. Bol. Tecn. PETROBRAS. 18(3/4): 115-127.

NASCIMENTO FILHO, GA. 2007. Desenvolvimento Estrutural e Padrão de Zonação dos Bosques de Mangue no rio Ariquindá, Baía de Tamandaré, Pernambuco, Brasil. Dissertation. Federal University of Pernambuco, Brazil.

NIMER, E. 1979. Pluviometria e recursos hídricos dos estados de Pernambuco e Paraíba. SUOREN, Rio de Janeiro. 117p.

NORIEGA, CD, KMP COSTA, MC ARAÚJO, RK TRAVASSOS \& S NEUMANN-LEITÃO. 2005a. Fluxos de nutrientes inorgânicos dissolvidos em um estuário tropical - Barra das Jangadas, PE, Brasil. Trop. Oceanogr. 33(2): 129-139.

NORIEGA, CD, KMP COSTA, FAN FEITOSA, MJ FLORES MONTES, CKS GREGO, GS SOARES \& HP SILVA. 2005b. Distribuição espacial da biomassa fitoplanctônica e sua relação com os sais nutrientes, no sistema estuarino de Barra das jangadas (Pernambuco - Brasil). Arq. Cienc. Mar. 38: 5-21.

PASSAVANTE, JZO, FAN FEITOSA, SJ MACÊDO, JOR ARAGÃO, S NEUMANN LEITÃO \& IC LINS. 2003. Produção, biomassa fitoplanctônica, climatologia e hidrologia do estuário do rio Botafogo, Itapissuma, Pernambuco. Bolm. Tecn. Cient. CEPENE. 11.

PLATT, T, DV SUBBA RAO \& B IRWING. 1983. Photosynthesis of picoplankton in the oligotrophic ocean. Nature. 301: 702-704.

ROHLF, FJ \& DL FISHER. 1968. Test for hierarclical structure in randon data sets. Systematical Zoology. 17: 107-412.

ROSEVEL DA SILVA, M, MGG SILVA-CUNHA \& FAN FEITOSA. 2004. Diversidade e riqueza das espécies da flora planctônica na baia de Tamandaré, litoral sul de Pernambuco, Brasil. Arq. Inst. Biol. 71(supl): 1-749.

SANTOS-FERNANDES, TL, JZO PASSAVANTE, ML KOENING \& SJ MACEDO. 1998. Fitoplâncton do estuário do rio Jaguaribe (Itamarcá, Pernambuco, Brasil): Biomassa. Trab. Oceanogr. Univ. Fed. Pe. 26: 1-18.

SANTOS-FERNANDES, TLS, JSO PASSAVANTE, ML KOENING, SJ MACÊDO \& LINS, I. C. 2000. Fitoplâncton do estuário do rio Jaguaribe, (Itamaracá, Pernambuco, Brasil): Produção e hidrologia. Rev. Ecol. Aq. Trop. 10: 1-145.

SMITH, VH. 2007. Using primary productivity as an index of coastal 
eutrophication: the units of measurement matter. J. Plankton Res. 29(1): 1-6.

SNOW, GC, JB ADAMS \& GC BATE. 2000. Effect of River Flow on Estuarine Microalgal Biomass and Distribution. Estuar. Coast. Shelf Sci. 51: 255-266.

SOUZA, EB, RS PAIVA, NFAC MELO, CAR RAMOS \& GD PALHETA. 2004. Composição e distribuição espacial do microfitoplâncton da plataforma continental norte: costa do estado do Pará (PROSPEC XXII, Revizee - 2001). I Congresso Brasileiro de Oceanografia e XIV Semana Nacional de Oceanografia. p. 118.

STEEMANN-NIELSEN, E. 1952. The use of radioactive Carbon $\left(\mathrm{C}^{14}\right)$ for measuring organic production in the sea. J. Cons. Perm. Intern. l' Explor. Mer. 18(2): 117 - 140.

STRICKLAND, J. D. H \& TRA PARSONS. 1972. Practical handbook of seawater analysis. 2 ed. Bul. Fish. Res. Board Can. 167: 207-211.

TUNDISI, JG \& TM TUNDISI. 1976. Produção orgânica em ecossistemas aquáticos. Cienc. Cult.. 28(8): 864-887
UNESCO. 1966. Determination of photosyntetic pigments in seawater. Rapor of SCOR/UNESCO, working group 17 with meat from 4 to 6 June 1964. Paris: (monography on Oceanography Methodology, 1). Paris, 69p.

UNESCO. 1973. International Oceanographic Table. Wormly. 2. $141 \mathrm{p}$

UNESCO. 1997. Phytoplankton pigments. In JEFREY, SW, RSC MANTORA, SW WRIGHT. (Eds). Oceanography. 661p

VARELA, M \& R PREGO. 2003. Hydrography and phytoplankton in an isolated and non-pristine ria area: the a Coruña Harbour (NW Spain). Acta Oecol. 24: 113-124.

VOLLENWEIDER, RA, JT TALLING \& DF WESTLAKE. 1974. A manual an method for measuring primary production in aquatic environment. $2^{\circ}$ ed. Blackwell Scientific Publication, Oxford, 225p.

WU JT \& TL CHOU. 2003. Silicate as the limiting nutrient for phytoplankton in a subtropical eutrophic estuary of Taiwan. Estuar. Coast. Shelf Sci. 58: 155-162 